\title{
Evidence for genetic association of RORB with bipolar disorder
} Casey L McGrath ${ }^{1,2}$, Stephen J Glatt ${ }^{3}$, Pamela Sklar ${ }^{1}$, Helen Le-Niculescu ${ }^{4}$, Ronald Kuczenski ${ }^{5}$, Alysa E Doyle ${ }^{6}$, Joseph Biedermann ${ }^{6}$, Eric Mick ${ }^{6}$, Stephen V Faraone ${ }^{3}$, Alexander B Niculescu ${ }^{* 4}$ and Ming T Tsuang*5

\begin{abstract}
Address: ${ }^{1}$ Center for Human Genetic Research, Massachusetts General Hospital, Boston, MA, USA, ${ }^{2}$ Department of Biology, Indiana University, Bloomington, IN, USA, ${ }^{3}$ Department of Psychiatry, SUNY Upstate Medical University, Syracuse, NY, USA, ${ }^{4}$ Laboratory of Neurophenomics, Department of Psychiatry, Indiana University School of Medicine, Indianapolis, IN, USA, 5 Department of Psychiatry, UC San Diego, La Jolla, CA, USA and ${ }^{6}$ Pediatric Psychopharmacology Unit, Massachusetts General Hospital; Psychiatric Psychopharmacology Unit, Massachusetts General Hospital, Harvard Medical School, Boston, MA, USA

Email: Casey L McGrath - mcgrath.casey@gmail.com; Stephen J Glatt - glatts@upstate.edu; Pamela Sklar - sklar@broad.mit.edu; Helen LeNiculescu - hlenicul@iupui.edu; Ronald Kuczenski - rkuczenski@ucsd.edu; Alysa E Doyle - doylea@helix.mgh.harvard.edu; Joseph Biederman - biederman@helix.mgh.harvard.edu; Eric Mick - emick1@partners.org; Stephen V Faraone - faraones@upstate.edu; Alexander B Niculescu* - anicules@iupui.edu; Ming T Tsuang* - mtsuang@ucsd.edu

* Corresponding authors
\end{abstract}

Published: 12 November 2009

BMC Psychiatry 2009, 9:70 doi:10.1 I86/147I-244X-9-70
Received: 4 March 2009

Accepted: 12 November 2009

This article is available from: http://www.biomedcentral.com/I47/ -244X/9/70

(C) 2009 McGrath et al; licensee BioMed Central Ltd.

This is an Open Access article distributed under the terms of the Creative Commons Attribution License (http://creativecommons.org/licenses/by/2.0), which permits unrestricted use, distribution, and reproduction in any medium, provided the original work is properly cited.

\begin{abstract}
Background: Bipolar disorder, particularly in children, is characterized by rapid cycling and switching, making circadian clock genes plausible molecular underpinnings for bipolar disorder. We previously reported work establishing mice lacking the clock gene D-box binding protein (DBP) as a stress-reactive genetic animal model of bipolar disorder. Microarray studies revealed that expression of two closely related clock genes, RAR-related orphan receptors alpha (RORA) and beta (RORB), was altered in these mice. These retinoid-related receptors are involved in a number of pathways including neurogenesis, stress response, and modulation of circadian rhythms. Here we report association studies between bipolar disorder and single-nucleotide polymorphisms (SNPs) in RORA and RORB.

Methods: We genotyped 355 RORA and RORB SNPs in a pediatric cohort consisting of a family-based sample of 153 trios and an independent, non-overlapping case-control sample of 152 cases and 140 controls. Bipolar disorder in children and adolescents is characterized by increased stress reactivity and frequent episodes of shorter duration; thus our cohort provides a potentially enriched sample for identifying genes involved in cycling and switching.

Results: We report that four intronic RORB SNPs showed positive associations with the pediatric bipolar phenotype that survived Bonferroni correction for multiple comparisons in the case-control sample. Three RORB haplotype blocks implicating an additional II SNPs were also associated with the disease in the case-control sample. However, these significant associations were not replicated in the sample of trios. There was no evidence for association between pediatric bipolar disorder and any RORA SNPs or haplotype blocks after multiple-test correction. In addition, we found no strong evidence for association between the age-at-onset of bipolar disorder with any RORA or RORB SNPs.
\end{abstract}

Conclusion: Our findings suggest that clock genes in general and RORB in particular may be important candidates for further investigation in the search for the molecular basis of bipolar disorder. 


\section{Background}

Bipolar disorder is often characterized by circadian rhythm abnormalities, including decreased need for sleep and rapid cycling and switching. This appears to be particularly true among pediatric bipolar patients, where cycling and switching is more rapid than among adult bipolar patients [1-3]. Decreased sleep has even been noted as one of the earliest symptoms discriminating children with bipolar disorder from those with attention deficit hyperactivity disorder (ADHD) [4]. For these reasons, circadian rhythm abnormalities in general, and circadian clock genes in particular, have been proposed as possible mechanistic underpinnings for bipolar disorder, particularly for the phenomena of cycling and switching [5-14]. Associations between seasonal affective disorder (SAD), a variant of bipolar disorder, and polymorphisms in the clock genes PER2, ARNTL/BMAL1, and NPAS2 have been reported $[15,16]$.

We previously described the identification of clock gene D-box binding protein $(D B P)$ as a potential candidate gene for bipolar disorder [6] using a Bayesian-like approach called Convergent Functional Genomics. In additional work where we used an expanded Convergent Functional Genomics approach in a mouse pharmacogenomic model for bipolar disorder, we identified a series of other clock genes (ARNTL/BMAL1, CRY2, CSNK1D, and CCR4/nocturnin) as potential bipolar candidate genes [17]. Two subsequent reports have shown some suggestive association for one of these genes, ARNTL/BMAL1, in human bipolar samples $[18,19]$. ARNTL/BMAL1 is upstream of $D B P$ in the circadian clock intracellular molecular machinery, driving the transcription of $D B P$ $[20,21]$.

To further assess the role of $D B P$ in bipolar and related disorders, we have conducted and recently reported behavioral and gene expression studies in mice with a constitutive homozygous deletion of $D B P$ (DBP KO mice) [14]. The studies in DBP KO mice revealed two other, closely related, clock genes whose expression levels were also altered: $R A R$-related orphan receptors alpha (RORA) and beta (RORB). Both RORA and RORB expression was increased in the amygdala and decreased in the pre-frontal cortex in DBP KO non-stressed, depressed-like mice. The $R O R$ proteins, retinoid-related transcription factors, are in the steroid hormone receptor superfamily and play regulatory roles in neurogenesis, bone metabolism, and circadian rhythms (reviewed in [22]). RORA expression is widespread and appears to oscillate rhythmically in some tissues [23]. One of its roles involves activating transcription of the clock gene ARNTL/BMAL1 and regulating its circadian oscillation [24]. Staggerer mutant mice, which lack RORA activity, exhibit an enhanced response to novel environmental stress, mediated through corticosterone circadian rhythm abnormalities [25]. Of note, corticoster- one abnormalities are prominent clinical findings in human affective disorder patients [26]. RORB expression is more limited than RORA and is highest in the eye, pineal gland, and brain, particularly in the primary sensory cortices (layer IV of the somatosensory cortex) and the suprachiasmatic nuclei of the hypothalamus (reviewed in $[22,27])$. Like RORA, RORB expression is known to change as a function of circadian rhythm in some tissues, and RORB -/- mice exhibit circadian rhythm abnormalities.

Here we report association studies for RORA and RORB in a pediatric bipolar disorder cohort. Bipolar disorder in children and adolescents is characterized by more rapid cycling and switching compared to adult bipolar disorder [1-3], possibly due to ongoing developmental processes and increased plasticity. Given our hypothesis that clock genes may underlie cycling and switching and the fact that $R O R$ proteins play a role in development and neurogenesis, we reasoned that a pediatric bipolar cohort may represent an enriched pool in which to test for genetic association with illness. We therefore genotyped 312 RORA and 43 RORB single-nucleotide polymorphisms (SNPs) in two pediatric bipolar sub-cohorts: a familybased sample of 153 trios (each trio consisting of an affected proband and both parents) and a case-control sample of 152 cases (all independent from the familybased samples) and 140 independent controls.

\section{Methods}

\section{Sample Identification}

Subjects were ascertained from families recruited for genetic studies of pediatric psychopathology at the Clinical and Research Program in Pediatric Psychopharmacology and Adult ADHD at Massachusetts General Hospital [28-31]. All study procedures were reviewed and approved by the subcommittee for human subjects of our institution. All subjects' parents or guardians signed written informed consent forms and children older than 7 years of age signed written assent forms.

Potential bipolar disorder I (BP-I) probands were ascertained from our clinical service, referrals from local clinicians, or self-referral in response to internal hospital advertisements. Subjects' parents were administered a phone screen reviewing symptoms of DSM-IV BP-I and, if criteria were met, subjects were scheduled for a face-toface structured diagnostic interview (described below). There were two sources of controls. The first group of controls was ascertained from outpatients referred for routine physical examinations to pediatric medical clinics at each setting identified from their computerized records as not having ADHD and who were found not to have BP-I on structured diagnostic interview. The second group of controls was selected from the Healthy Volunteer Specimen Bank (HVS) at the Harvard Medical School-Partners 
Healthcare Center for Genetics and Genomics. Healthy volunteers had also signed informed consent specifically allowing future DNA analyses. A thorough medical history and physical exam was performed to exclude all active diseases and current medication use and to obtain information such as lifetime tobacco use (yes or no). Controls were excluded if they had either ADHD or BPD. Other psychiatric disorders were not used as exclusion criteria.

\section{Diagnostic Procedures}

All affected probands in the current analysis were diagnosed with bipolar I disorder according to DSM-IV criteria. The DSM-IV requires subjects to meet criterion A for a distinct period of extreme and persistently elevated, expansive, or irritable mood lasting at least one week, plus criterion B, manifested by three (four if the mood is irritable only) of seven symptoms during the period of mood disturbance. Also recorded was the onset of first episode, the number of episodes, offset of last episode, and total duration of illness. Psychiatric assessments of child family members (younger than 18 years) were made with the KSADSE (Epidemiologic Version) [32] and assessments of adult family members were made with the Structured Clinical Interview for DSM-IV [33]. Diagnoses were based on independent interviews with mothers and direct interviews with the children older than 12 years of age. Data were combined such that endorsement by either reporter resulted in a positive diagnosis. Interviews were conducted by extensively trained and supervised psychometricians with undergraduate degrees in psychology. This training involved several weeks of classroom instruction of interview mechanics, diagnostic criteria, and coding algorithms. They also observed interviews by experienced raters and clinicians and were observed while conducting interviews during the final training period. A committee of three psychiatrists, each board-certified in both child and adult psychiatry, resolved all diagnostic uncertainties. The committee members were blind to the subjects' ascertainment group, ascertainment site, and data collected from family members.

Probands were selected for analysis if the age-at-onset of bipolar disorder was 18 years or younger. The sample for family-based association analysis consisted of 153 affected probands (age (mean \pm S.D.): $17.5 \pm 11.6$ years; BP-I onset: $7.7 \pm 4.9$ years) and both parents (153 trios); the sample for case-control association analysis consisted of 152 independent, non-overlapping cases (age: $20.3 \pm$ 12.1 years; BP-I onset: $9.1 \pm 5.0$ years) and 140 controls (age: $42.9 \pm 10.3$ years). Thus the combined samples comprised 305 BP-I probands. Within our sample, 97.5\% (N $=429)$ of individuals in trios, $98.0 \%(\mathrm{~N}=147)$ of cases and $89.4 \%(\mathrm{~N}=118)$ of controls were Caucasian.

\section{SNP Tagging and Genotyping}

SNP genotype information for the CEPH population (Utah residents of northern and western European ancestry) was downloaded from the Phase II HapMap data (release \#20) for regions surrounding each gene $(750.7 \mathrm{~kb}$ for RORA and $208.1 \mathrm{~kb}$ for RORB). We used the Tagger program as implemented in Haploview http:// www.broad.mit.edu/mpg/haploview/[34] to select pairwise tag-SNPs with minor allele frequencies $(\mathrm{MAF})=0.05$ and an $r^{2}$ threshold of 0.8 . In total, 332 tag-SNPs from RORA (99\% of alleles captured; mean $\left.r^{2}=0.959\right)$ and 44 tag-SNPs from RORB (98\% of alleles captured; mean $r^{2}=$ 0.959) were chosen for genotyping. Primers were designed using MassARRAY's Assay Design software (Bruker-Sequenom, USA) and were purchased from Integrated DNA Technologies (USA). Genotyping of samples was performed as single-base extension reactions (iPLEX) using the MassARRAY mass spectrometry system as previously described [35]. A list of the genotyped SNPs and the assay primers used can be found in Additional file 1.

\section{Data Analysis}

A number of quality control measures were implemented to ensure accuracy of the data collected. Genotypes from intra- and inter-plate controls were compared for identity, and negative test controls were confirmed to have no genotypes called. In addition, assays that failed in over $10 \%$ of the samples (14 SNPs) were excluded and samples that failed in over $10 \%$ of the assays (33 samples) were excluded. The genotyping rate in the remaining individuals was $99.38 \%$. Families with greater than 5\% Mendelian errors (4 families) and SNPs with greater than 10\% Mendelian errors (1 SNP) were excluded, and genotypes causing remaining Mendelian errors were set to missing. SNPs out of Hardy-Weinberg Equilibrium $(P<0.001 ; 6$ SNPs) were excluded from analysis. These measures resulted in a final set of 312 RORA SNPs (93\% of alleles captured; mean $\left.r^{2}=0.959\right)$, and 43 RORB SNPs (98\% of alleles captured; mean $r^{2}=0.959$ ).

Family-based transmission disequilibrium tests (TDT) and case-control association tests were conducted independently on the two sample sets using the program PLINK http://pngu.mgh.harvard.edu/ purcell/plink/[36]. Bonferroni correction for multiple testing was implemented based on the number of SNPs analyzed per gene. The critical $P$-value for a positive association was therefore $1.6 \times 10^{-4}$ for SNPs from RORA and $1.2 \times 10^{-3}$ for SNPs from $R O R B$. In addition to these separate analyses for the case-control and the family-based samples, a combined odds ratio for the two sample sets was determined via the method described in Kazeem and Farrall [37]. Haplotype analyses were performed for both sample sets using the Confidence Intervals algorithm in Haploview [34,38]. Haplotype block associations were considered significant 
with a two-tailed permutation-based $P$-value $<0.05$ after 1000 permutations.

Association with genotyped SNPs and age-at-onset (AAO) of bipolar disorder was analyzed by performing a quantitative trait analysis using the option afam in PLINK. This option takes into account family structure information, so we were able to include data from the family-based sample and the case-control sample in the same analysis. The AAO phenotype was set to missing for all controls. Results were considered significant with a permutation-based $P$ value $<0.05$ after 1000 permutations.

\section{Results}

Several SNPs reached the nominal significance level of $P<$ 0.05 in either the family-based sample or the case-control sample: 18 RORA SNPs and 8 RORB SNPs in the familybased sample, and 13 RORA SNPs and 16 RORB SNPs in the case-control sample [see Additional file 2]. However, after Bonferroni correction for multiple testing, no RORA SNPs and 4 RORB SNPs remained significant. These RORB SNPs were rs1157358 $\left(P=4.5 \times 10^{-5}\right)$ and rs7022435 $(P=$ $\left.1.1 \times 10^{-6}\right)$ in intron $1, \operatorname{rs} 3750420\left(P=7.9 \times 10^{-6}\right)$ in intron 2 , and rs3903529 $\left(P=8.2 \times 10^{-5}\right)$ in intron 4 (Figure 1). All of these SNPs were significant only in the casecontrol sample and exhibited odds ratios in the opposite direction in the family-based sample (Table 1). No SNP exhibited a combined family-based/case-control $P$-value $<$ 0.05. Of the four SNPs significant in the case-control sample, all but one exhibited Hardy-Weinberg Equilibrium (HWE) $P$-values $>0.05$ in both sample sets; the exception is rs 3750420 , for which the family-based HWE $P$-value was 0.037 (HWE $P=0.100$ in case-control sample). The genotyping call rates for these four SNPs were between $97.66 \%$ and $100 \%$ in both cases and controls, and there were no significant differences in call rates between cases and controls (Fisher's exact test, all $P$-values $>0.05$ ). Three RORB haplotype blocks in the case-control sample exhibited permuted $P$-values $<0.05$ (blocks 5 and $6, P<0.001$; block $8, P=0.002$ ) (Figure 1 and Table 2). No RORB haplotype blocks in the family-based sample and no RORA haplotype blocks in the family-based or case-control samples remained significant after permutation.

While our failure to replicate the association between RORB SNPs and bipolar disorder in the trios sample could be due to the fact that case-control designs exhibit higher power than family-based designs, it also raises the possibility that our results were due to population stratification within the case-control sample, particularly as there was a higher percentage of non-Caucasians among the controls $(10.6 \%)$ than among the cases $(2.0 \%)$. To investigate this possibility, we reran the SNP association analysis on the case-control data after removing all non-Caucasian individuals (and those with missing information) from the dataset, leaving a sample of 147 cases and 118 controls.
All four RORB SNPs that were significant in the original sample remained significant after Bonferroni correction on the filtered Caucasian-only sample. An additional RORB SNP, rs7032677, was also significant after correction in this limited sample $(\mathrm{P}=1.99 \times 10-4$ in this sample, $\mathrm{P}=0.0021$ in the original sample).

For quantitative trait analysis with age-at-onset, 8 RORA and 2 RORB SNPs exhibited significant $P$-values after permutation [lowest $P$-values per gene: rs7175393 $(P=$ $0.025)$ in RORA and rs $12001830(P=0.037)$ in RORB; see Additional file 3]. The two significant SNPs from RORB from the AAO analysis, however, were not among the SNPs associated with the bipolar disorder "affected" phenotype used in the primary analysis reported above.

\section{Discussion}

We identified a potential association between bipolar disorder and the retinoid-related receptor $R O R B$ in a pediatric bipolar disorder cohort. Four RORB SNPs and three haplotype blocks demonstrated positive associations in the case-control sample after Bonferroni correction or permutation. RORB was initially chosen for investigation due to its altered expression level in DBP knock-out mice (an animal model of bipolar disorder [14]) and due to the potential role of circadian clock genes in bipolar disorder.

The RORB gene encodes two isoforms, RORB1 and RORB2, which differ only in their N-terminal domains [39]. These alternative forms have different first exons and are believed to be produced as a result of transcription from alternative promoters. In RORB1, nine amino acids precede the first cysteine of the DNA binding domain, while in RORB2 there are twenty residues before this cysteine. The two forms of the protein exhibit differential expression patterns: RORB2 is found exclusively in the retina and pineal gland, and RORB1 is found mainly in the cerebral cortex (particularly in layer IV and, to a lesser extent, layer V), thalamus, and hypothalamus and is expressed only at very low levels in the retina and pineal gland $[39,40]$. RORB2 mRNA expression oscillates dramatically with circadian rhythms, peaking during the hours of darkness, while RORB1 expression fluctuates only mildly [39]. The DNA binding specificities and activities of the isoforms also differ. In rat, this results in $R O R B 2$ demonstrating increased activity in non-neuronal cells, though RORB1 and RORB2 perform equally well in neuroblastoma cells [39]. Taken together, these findings indicate that RORB1 is likely responsible for functions relating to the processing of sensory input while RORB2 is an integral member of the circadian clock machinery.

The four intronic SNPs of RORB we found to be associated with bipolar disorder are all downstream of the first exon in both RORB1 and RORB2 transcripts. If certain sequence variants of RORB (these SNPs or others in linkage disequilib- 


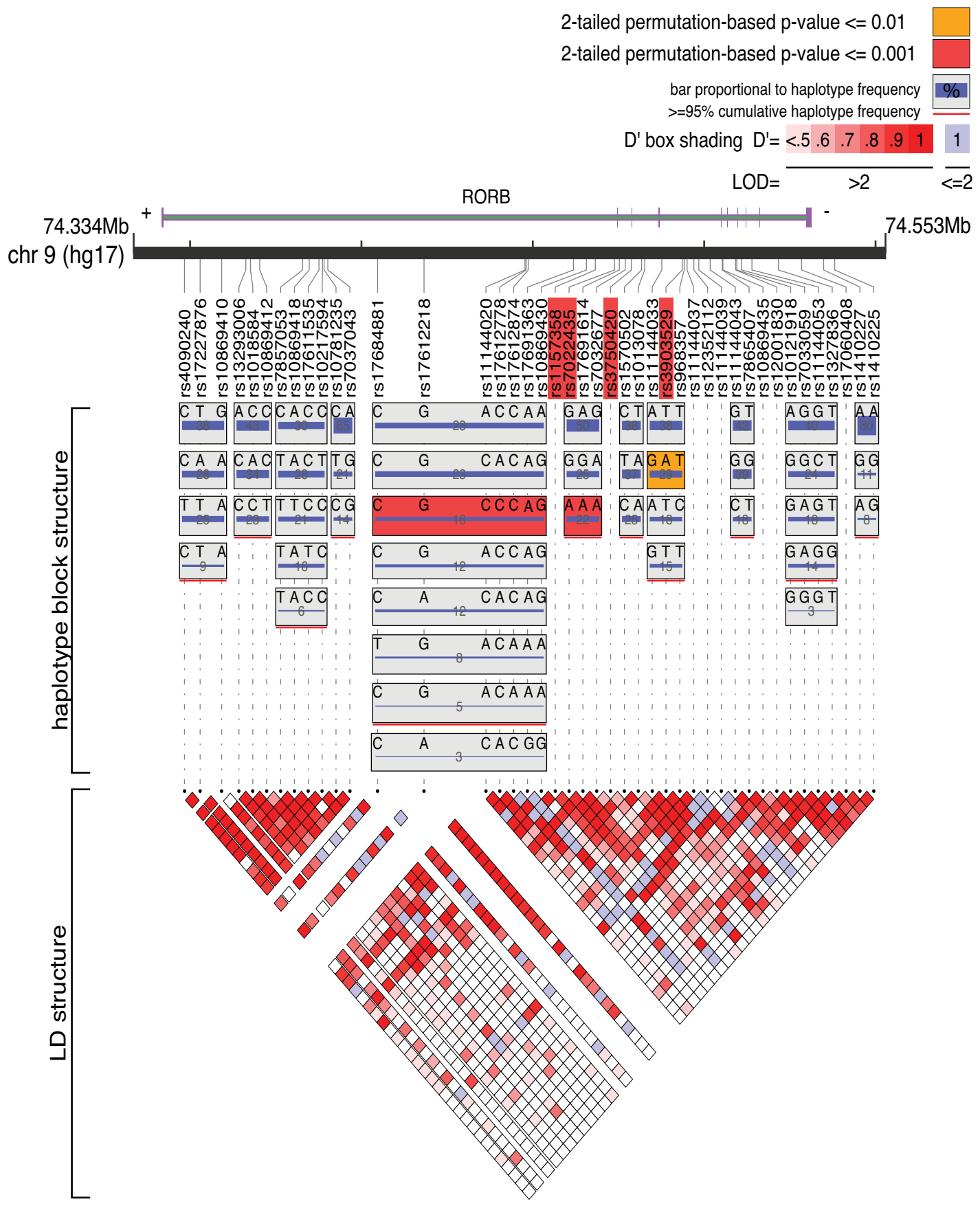

\section{Figure I}

Genomic Organization of RORB with Association Results. The genomic location and organization of RORB are shown, with exons represented by vertical purple bars. All 43 analyzed RORB SNPs are shown and their positions are indicated. The four SNPs with significant associations to bipolar disorder in the case-control sample are highlighted in red. The haplotype block structure in the case-control sample as defined by the Confidence Intervals algorithm [38] in Haploview [34] is illustrated, with the linkage disequilibrium (LD) structure shown below. The two haplotype blocks with two-tailed permutationbased $P$-values $<0.00 \mathrm{I}$ are highlighted in red, and the block with $P<0.0 \mathrm{I}$ is highlighted in orange. Image created using LocusView http://www.broad.mit.edu/mpg/locusview/[5I]. 
Table I: RORB SNPs with Significant Association to Bipolar Disorder.

\begin{tabular}{|c|c|c|c|c|c|c|c|c|c|c|c|c|c|c|c|}
\hline SNP & Region & $\begin{array}{l}\text { Minor } \\
\text { Allele }\end{array}$ & $\begin{array}{l}\text { Major } \\
\text { Allele }\end{array}$ & $\begin{array}{l}\text { Case- } \\
\text { Control } \\
\text { MAF }\end{array}$ & $\begin{array}{l}\text { Case } \\
\text { MAF }\end{array}$ & $\begin{array}{c}\text { Control } \\
\text { MAF }\end{array}$ & $\begin{array}{l}\text { Case- } \\
\text { Control } \\
\text { OR }\end{array}$ & $\begin{array}{l}\text { Case- } \\
\text { Control } \\
P \text {-value }\end{array}$ & $\begin{array}{l}\text { TDT MAF } \\
\text { (Founders) }\end{array}$ & $\mathbf{T}$ & $\mathbf{U}$ & $\begin{array}{c}\text { TDT } \\
\text { OR }\end{array}$ & $\begin{array}{c}\text { TDT } \\
P \text {-value }\end{array}$ & $\begin{array}{c}\text { Combined } \\
\text { OR }\end{array}$ & $\begin{array}{c}\text { Combined } \\
P \text {-value }\end{array}$ \\
\hline rsII57358 & Intron I & $\mathrm{T}$ & C & 0.137 & 0.218 & 0.091 & 2.802 & 4.5E-05 & 0.167 & 29 & 38 & 0.763 & 0.272 & 1.162 & 0.401 \\
\hline rs7022435 & Intron I & A & G & 0.176 & 0.310 & 0.135 & 2.881 & I.IE-06 & 0.203 & 34 & 51 & 0.667 & 0.065 & 1.150 & 0.373 \\
\hline rs3750420 & Intron 2 & $\mathrm{~T}$ & C & 0.237 & 0.375 & 0.201 & 2.388 & 7.9E-06 & 0.304 & 65 & 66 & 0.985 & 0.930 & 1.176 & 0.214 \\
\hline rs3903529 & Intron 4 & $A$ & $\mathrm{~T}$ & 0.229 & 0.357 & 0.205 & 2.154 & $8.2 \mathrm{E}-05$ & 0.247 & 34 & 55 & 0.618 & 0.026 & 1.094 & 0.537 \\
\hline
\end{tabular}

$\mathrm{MAF}=$ Minor Allele Frequency

$\mathrm{OR}=$ Odds Ratio of the minor allele

$\mathrm{T}=$ Number of transmitted minor allele

$U=$ Number of untransmitted minor alleles

rium with them) do indeed represent susceptibility variants for bipolar disorder, it is possible they do so by altering the expression of one or both of the RORB isoforms. One of the haplotype blocks exhibiting a positive association (block 5 in Figure 1 and Table 2) spans the region containing the RORB2 exon 1, from approximately $55.1 \mathrm{~kb}$ upstream to approximately $5.7 \mathrm{~kb}$ downstream of RORB2 exon 1 . It is possible, therefore, that the positive signal in this haplotype is due to sequence variation in the RORB2 promoter that affects the location, timing, or magnitude of RORB2 expression, leading to increased risk for bipolar disorder.

Our findings should be considered in the context of important methodological limitations. Although our patient sample was relatively small, its focus on pediatric patients made it a potentially enriched pool in which to search for genes involved in rapid cycling and switching, such as clock genes. The significant association of four RORB SNPs and three RORB haplotype blocks with bipolar disorder in the case-control sample indicates that this may indeed be the case. However, the TDT odds ratios for the associated SNPs were not consistent with the highly significant case-control results. This raises the possibility that the case-control results could be false positives due to population stratification or that we had insufficient power in our replication sample.
Though we still observed significant association after limiting the sample to Caucasians only, we cannot rule out other sources of stratification, such as distinct ancestry. Alternatively, these findings could be the result of associated alleles of each marker on different haplotypes with the actual risk-conferring variant(s) in the two samples.

Despite these limitations, our results indicate that circadian clock genes in general and $R O R B$ in particular may be important candidates for genes involved in bipolar disorder. Of note, both RORB and RORA have nominally suggestive signals in three recently reported genome-wide association studies for bipolar disorder [41-43] that do not survive correction for multiple comparisons. This would be expected if our pediatric cohort does indeed represent an enriched sample in which to test for association with circadian clock genes that may be involved in cycling and switching. The nominally associated SNPs in RORB from these studies, however, do not overlap with those SNPs found to be associated in our study [see Additional file 4]. It is therefore necessary to verify these association results in other independent samples and to continue to study the relationship between $R O R B$, other clock genes, and bipolar disorder.

Table 2: RORB Haplotype Blocks with Significant Association to Bipolar Disorder.

\begin{tabular}{|c|c|c|c|c|c|c|c|}
\hline Block & SNPs & Haplotype & Overall Frequency & Case Frequency & Control Frequency & $P$-value & Permuted $P$-value \\
\hline \multirow[t]{7}{*}{ Block 5} & rs I768488I & CGCCCAG & 0.16 & 0.218 & 0.091 & $5.08 \mathrm{E}-05$ & $<0.001$ \\
\hline & rs 17612218 & & & & & & \\
\hline & rsIII44020 & & & & & & \\
\hline & rs $176 \mid 2778$ & & & & & & \\
\hline & rs I76I2874 & & & & & & \\
\hline & rs17691363 & & & & & & \\
\hline & rs 10869430 & & & & & & \\
\hline \multirow[t]{3}{*}{ Block 6} & rs7022435 & AAA & 0.224 & 0.305 & 0.13 & $8.17 \mathrm{E}-07$ & $<0.001$ \\
\hline & rs 17691614 & & & & & & \\
\hline & rs7032677 & & & & & & \\
\hline \multirow[t]{3}{*}{ Block 8} & rsIII44033 & GAT & 0.289 & 0.359 & 0.207 & $8.92 \mathrm{E}-05$ & 0.002 \\
\hline & rs3903529 & & & & & & \\
\hline & rs968357 & & & & & & \\
\hline
\end{tabular}


Finally, it is important to note that RORB, RORA, and DBP were identified by us recently as possible genes involved in schizophrenia using a pharmacogenomic mouse model and CFG approach [44]. Overall, our findings are thus consistent with a model of heterogeneity, overlap, and interdependence of major psychiatric disorders $[14,45,46]$. Particularly intriguing from a translational standpoint is the possibility that the localized expression of RORB in layer IV somatosensory cortex [47] may contribute to integration of external and internal stimuli that have a bearing on response to stress, mood reactivity, and cognitive constructs in bipolar disorder pathophysiology [48-50].

\section{Conclusion}

Our findings suggest that clock genes in general and RORB in particular may be important candidates for further investigation in the search for the molecular basis of bipolar disorder. These results are supported by our current understanding of the expression, localization, and possible roles of RORB in the brain and are also consistent with data from animal models of bipolar disorder.

\section{Competing interests}

The authors declare that they have no competing interests related to this work.

\section{Authors' contributions}

CLM conducted the genotyping experiments; PS supervised the genotyping experiments; CLM, SJG, and SVF contributed to data analysis; AED, EM, and JB contributed to sample collection and characterization; ABN, HLN, RK, and MTT contributed to the overall design of the project and candidate gene selection. CLM, PS, SJG, SVF, EM, ABN, HLN, RK, and MTT contributed to the writing of the manuscript. All authors read and approved the final manuscript.

\section{Additional material}

\section{Additional file 1}

Genotyped SNPs and assay primer sequences. This table lists the SNPs genotyped and includes sequences of the assay primers used for genotyping.

Click here for file

[http://www.biomedcentral.com/content/supplementary/1471244X-9-70-S1.doc]

\section{Additional file 2}

Association results for all analyzed RORA and RORB SNPs. This table details the association results for all RORA and RORB SNPs analyzed and includes results from both case-control and family-based samples. Click here for file

[http://www.biomedcentral.com/content/supplementary/1471244X-9-70-S2.doc]

\section{Additional file 3}

Association results for age-at-onset quantitative trait analysis. This table contains the results of the quantitative trait association analyses of RORA and RORB SNPs with age-at-onset of bipolar disorder.

Click here for file

[http://www.biomedcentral.com/content/supplementary/1471-

244X-9-70-S3.doc]

\section{Additional file 4}

RORB SNPs associated with bipolar disorder in genome-wide association studies. This table contains the P-values of RORB SNPs associated with bipolar disorder in our study and four genome-wide association analyses.

Click here for file

[http://www.biomedcentral.com/content/supplementary/1471244X-9-70-S4.doc]

\section{Acknowledgements}

This work was supported by a grant (I ROI MH 07/9|2) from the U.S. National Institute of Mental Health to MTT and NARSAD Mogens Schou Young Investigator award to $A B N$.

\section{References}

I. Geller B, Williams M, Zimerman B, Frazier J, Beringer L, Warner K. Prepubertal and early adolescent bipolarity differentiate from ADHD by manic symptoms, grandiose delusions, ultrarapid or ultradian cycling. J Affect Disord 1998, 5 I:8I-91.

2. Biederman J, Mick E, Faraone S, Van Patten S, Burback M, Wozniak J: A prospective follow up study of pediatric bipolar disorder in boys with attention deficit/hyperactivity disorder. J Affect Disord 2004, 82S:SI7-S23.

3. Biederman J, Faraone S, Wozniak J, Mick E, Kwon A, Cayton G, Clark $\mathrm{S}$ : Clinical correlates of bipolar disorder in a large, referred sample of children and adolescents. J Psychiatr Res 2005, 39:6II-622.

4. Luckenbaugh DA, Findling RL, Leverich GS, Pizzarello SM, Post RM: Earliest symptoms discriminating juvenile-onset bipolar illness from ADHD. Bipolar Disorders 2009, I I:44I-45I.

5. Bunney W, Bunney B: Molecular clock genes in man and lower animals: Possible implications for circadian abnormalities in depression. Neuropsychopharmacology 2000, 22(4):335-345.

6. Niculescu A, Segal D, Kuczenski R, Barrett T, Hauger R, Kelsoe J: Identifying a series of candidate genes for mania and psychosis: a convergent functional genomics approach. Physiol Genomics 2000, 4(I):83-9I.

7. Wager-Smith K, Kay S: Circadian rhythm genetics: from flies to mice to humans. Nat Genet 2000, 26(I):23-27.

8. Niculescu A, Kelsoe J: Convergent functional genomics: application to bipolar disorder. Ann Med 200I, 33(4):263-27I.

9. Kelsoe J, Niculescu A: Finding genes for bipolar disorder in the functional genomics era: from convergent functional genomics to phenomics and back. CNS Spectr 2002.

10. Lenox R, Gould T, Manji H: Endophenotypes in bipolar disorder. Am J Med Genet B 2002, I I 4(4):39|-406.

II. Hasler G, Drevets W, Gould T, Gottesman I, Manji H: Toward constructing an endophenotype strategy for bipolar disorders. Biol Psychiatry 2006, 60(2):93-105.

12. Wirz-Justice A: Biological rhythm disturbances in mood disorders. Int Clin Psychopharmacol 2006, 2 I (SuppI I):SI I-SI5.

13. McClung $\mathrm{C}$ : Circadian genes, rhythms and the biology of mood disorders. Pharmacol Ther 2007, I I 4(2):222-232.

14. Le-Niculescu H, McFarland M, Ogden C, Balaraman Y, Patel S, Tan J, Rodd Z, Paulus M, Geyer M, Edenberg H, et al:: Phenomic, convergent functional genomic, and biomarker studies in a stressreactive genetic animal model of bipolar disorder and comorbid alcoholism. Am J Med Genet B 2008, I47B(2): I34-I66. 
15. Johansson C, Willeit M, Smedh C, Ekholm J, Paunio T, Kieseppa T, Lichtermann D, Praschak-Rieder N, Neumeister A, Nilsson LG, et al: Circadian clock-related polymorphisms in seasonal affective disorder and their relevance to diurnal preference. Neuropsychopharmacology 2003, 28(4):734-739.

16. Partonen T, Treutlein J, Alpman A, Frank J, Johansson C, Depner M, Aron L, Rietschel M, Wellek S, Soronen P, et al.: Three circadian clock genes Per2, Arntl, and Npas2 contribute to winter depression. Ann Med 2007, 39(3):229-238.

17. Ogden CA, Rich ME, Schork NJ, Paulus MP, Geyer MA, Lohr JB, Kuczenski R, Niculescu AB: Candidate genes, pathways and mechanisms for bipolar (manic-depressive) and related disorders: an expanded convergent functional genomics approach. Mol Psychiatry 2004, 9(I I): 1007-1029.

18. Mansour HA, Wood J, Logue T, Chowdari KV, Dayal M, Kupfer D, Monk TH, Devlin B, Nimgaonkar VL: Association study of eight circadian genes with bipolar I disorder, schizoaffective disorder and schizophrenia. Genes Brain Behav 2006, 5(2):150-157.

19. Nievergelt CM, Kripke DF, Barrett TB, Burg E, Remick RA, Sadovnick $A D$, McElroy SL, Keck PE Jr, Schork NJ, Kelsoe JR: Suggestive evidence for association of the circadian genes PERIOD3 and ARNTL with bipolar disorder. Am J Med Genet B Neuropsychiatr Genet 2006, 14I(3):234-24I.

20. Ripperger JA, Schibler U: Rhythmic CLOCK-BMALI binding to multiple E-box motifs drives circadian Dbp transcription and chromatin transitions. Nat Genet 2006, 38(3):369-374.

21. Veen DR van der, Minh NL, Gos P, Arneric M, Gerkema MP, Schibler $U$ : Impact of behavior on central and peripheral circadian clocks in the common vole Microtus arvalis, a mammal with ultradian rhythms. Proc Natl Acad Sci USA 2006, 103(9):3393-3398.

22. Jetten A, Kurebayashi S, Ueda E: The ROR nuclear orphan receptor subfamily: Critical regulators of multiple biological processes. Prog Nucleic Acid Res Mol Biol 200I, 69:205-247.

23. Yang X, Downes M, Yu R, Bookout A, He W, Straume M, Mangelsdorf $D$, Evans R: Nuclear receptor expression links the circadian clock to metabolism. Cell 2006, I 26(4):80I-8I0.

24. Akashi M, Takumi T: The orphan nuclear receptor RORA regulates circadian transcription of the mammalian core-clock BMALI. Nat Struct Mol Biol 2005, I 2:44 I-448.

25. Frederic F, Chianale C, Oliver C, Mariani J: Enhanced endocrine response to novel environment stress and lack of corticosterone circadian rhythm in staggerer (Rora sg/sg) mutant mice. J Neurosci Res 2006, 83(8): 1525 - 1532

26. Arana GW, Wilens TE, Baldessarini RJ: Plasma corticosterone and cortisol following dexamethasone in psychiatric patients. Psychoneuroendocrinology 1985, I O(I):49-60

27. Jetten A, Ueda E: Retinoid-related orphan receptors (RORs): roles in cell survival, differentiation and disease. Cell Death Differ 2002, 9: ||67-||17|.

28. Biederman J, Faraone SV, Keenan K, Benjamin J, Krifcher B, Moore C Sprich-Buckminster S, Ugaglia K, Jellinek MS, Steingard R, et al.: Further evidence for family-genetic risk factors in attention deficit hyperactivity disorder. Patterns of comorbidity in probands and relatives in psychiatrically and pediatrically referred samples. Arch Gen Psychiatry 1992, 49(9):728-738.

29. Biederman J, Faraone SV, Mick E, Williamson S, Wilens TE, Spencer TJ, Weber W, Jetton J, Kraus I, Pert J, et al.: Clinical correlates of ADHD in females: findings from a large group of girls ascertained from pediatric and psychiatric referral sources. J Am Acad Child Adolesc Psychiatry 1999, 38(8):966-975.

30. Faraone SV, Biederman J, Spencer TJ, Mick E, Murray K, Petty C, Adamson J], Monuteaux MC: Diagnosing adult attention deficit hyperactivity disorder: are late onset and subthreshold diagnoses valid? Am J Psychiatry 2006, I63(10): I720-I729.

31. Wozniak J, Biederman J, Kwon A, Mick E, Faraone SV, Orlovsky K, Schnare L, Cargol C, Van Grondelle A: How cardinal are cardinal symptoms in pediatric bipolar disorder?: An examination of clinical correlates. Biol Psychiatry 2005, 58(7):583-588.

32. Orvaschel H: Schedule for Affective Disorder and Schizophrenia for School-Age Children Epidemiologic Version 5th edition. Ft. Lauderdale: Nova Southeastern University, Center for Psychological Studies; 1994

33. First MB, Spitzer RL, Gibbon M, Williams JBW: Structured Clinical Interview for DSM-IV Axis I Disorders-Clinician Version (SCID-CV) Washington, DC: American Psychiatric Press; 1997.
34. Barrett J, Fry B, Maller J, Daly M: Haploview: analysis and visualization of LD and haplotype maps. Bioinformatics 2005, 2I(2):263-265.

35. Sklar P, Gabriel S, Mclnnis M, Bennett P, Lim Y, Tsan G, Schaffner S, Kirov G, Jones I, Owen M, et al.: Family-based association study of 76 candidate genes in bipolar disorder: BDNF is a potential risk locus. Mol Psychiatry 2002, 7(6):579-593.

36. Purcell S, Neale B, Todd-Brown K, Thomas L, Ferreira M, Bender D, Maller J, Sklar P, de Bakker P, Daly M, et al.: PLINK: A tool set for whole-genome association and population-based linkage analyses. Am J Hum Genet 2007, 8 I (3):559-575.

37. Kazeem G, Farrall M: Integrating case-control and TDT studies. Ann Hum Genet 2005, 69:329-335.

38. Gabriel S, Schaffner S, Nguyen H, Moore J, Roy J, Blumenstiel B, Higgins J, DeFelice M, Lochner A, Faggart M, et al:: The structure of haplotype blocks in the human genome. Science (Wash) 2002, 296(5576):2225-2229.

39. Andre E, Gawlas K, Steinmayr M, Becker-Andre M: A novel isoform of the orphan nuclear receptor $\operatorname{ROR} \beta$ is specifically expressed in pineal gland and retina. Gene 1998, 216:277-283.

40. Schaeren-Wiemers N, Andre E, Kapfhammer J, Becker-Andre M: The expression pattern of the orphan nuclear receptor ROR $\beta$ in the developing and adult rat nervous system suggests a role in the processing of sensory information and in circadian rhythm. Eur J Neurosci 1997, 9:2687-270I.

4I. Sklar P, Smoller JW, Fan J, Ferreira MAR, Perlis RH, Chambert K, Nimgaonkar VL, McQueen MB, Faraone SV, Kirby A, et al.: Wholegenome association study of bipolar disorder. Mol Psychiatry 2008, 13(6):558-569.

42. Wellcome Trust Case Control Consortium: Genome-wide association study of 14,000 cases of seven common diseases and 3,000 shared controls. Nature 2007, 447(7 I 45):66I-678.

43. Baum AE, Akula N, Cabanero M, Cardona I, Corona W, Klemens B, Schulze TG, Cichon S, Rietschel M, Nothen MM, et al: A genomewide association study implicates diacylglycerol kinase eta (DGKH) and several other genes in the etiology of bipolar disorder. Mol Psychiatry 2008, I3(2): 197-207.

44. Le-Niculescu H, Balaraman Y, Patel S, Tan J, Sidhu K, Jerome RE, Edenberg HJ, Kuczenski R, Geyer MA, Nurnberger Jl Jr, et al: Towards understanding the schizophrenia code: An expanded convergent functional genomics approach. $\mathrm{Am} J$ Med Genet B Neuropsychiatr Genet 2007, I 44(2): I29-158.

45. Niculescu AB, Lulow LL, Ogden CA, Le-Niculescu H, Salomon DR, Schork NJ, Caligiuri MP, Lohr JB: PhenoChipping of psychotic disorders: A novel approach for deconstructing and quantitating psychiatric phenotypes. Am J Med Genet B Neuropsychiatr Genet 2006, 141(6):653-662.

46. Niculescu AB: Polypharmacy in oligopopulations: what psychiatric genetics can teach biological psychiatry. Psychiatr Genet 2006, I6(6):24I-244.

47. Carson JP, Ju T, Lu HC, Thaller C, Xu M, Pallas SL, Crair MC, Warren J, Chiu W, Eichele G: A digital atlas to characterize the mouse brain transcriptome. PLoS Comp Biol 2005, I (4):289-296.

48. Marchand WR, Wirth L, Simon C: Adverse life events and pediatric bipolar disorder in a community mental health setting. Community mental health journal 2005, 4I(I):67-75.

49. Alloy LB, Abramson LY, Walshaw PD, Keyser J, Gerstein RK: A cognitive vulnerability-stress perspective on bipolar spectrum disorders in a normative adolescent brain, cognitive, and emotional development context. Development and psychopathology 2006, I8(4): 1055-II03.

50. Kim EY, Miklowitz DJ, Biuckians A, Mullen K: Life stress and the course of early-onset bipolar disorder. Journal of affective disorders 2007, 99(I-3):37-44

5I. Petryshen T, Kirby A, Ainscow M: LocusView. [http://www.broad institute.org/mpg/locusview]. unpublished software

\section{Pre-publication history}

The pre-publication history for this paper can be accessed here:

\section{http://www.biomedcentral.com/1471-244X/9/70/pre} pub 